\title{
O EDITO DOS CENSORES CONTRA OS LATINI RHETORES: MOTIVAÇÕES E CONSEQUENCIAS
}

\author{
Felipe Epprecht Douverny \\ Centro Universitário Campo Real, Paraná
}

\begin{abstract}
RESUMO: O presente trabalho tem como objetivo analisar o edito emanado pelos censores romanos no ano de 92 a.C. contra os rétores latinos, tratar de suas motivações e tentar responder, com base na análise dos poderes exercidos pelos censores ao atuar no controle dos costumes romanos (regimen morum), a uma questão bastante debatida na literatura sobre a história da disciplina da retórica em Roma, qual seja, saber se referido edito causou o fechamento das escolas dos Latini rhetores.
\end{abstract}

PALAVRAS-CHAVE: Direito Romano. Censores. Edito. Rétores latinos. Regimen morum. Nota censoria.

\section{The censors' edict against the Latini rhetores: motivations and consequences}

\begin{abstract}
This paper seeks to analyze the edict issued by the roman censors in $92 \mathrm{BC}$ against the Latin rhetoricians, deal with its motivations and try to answer, based on the analysis of the powers exercised by the censors when controlling roman custom (regimen morum), a much debated question in the literature concerning the history of Rhetoric in Rome, that is, knowing if such edict has caused the closing of the schools of the Latini rhetores.
\end{abstract}

KEYWORDS: Roman Law. Censors. Edict. Latin rhetoricians. Regimen morum. Nota censoria.

\section{INTRODUÇÃO}

Embora a disciplina da retórica tenha sido valorizada na Roma republicana, as relações entre os professores da matéria e o governo da civitas nem sempre foram pacíficas. Em 161 a.C., um senatusconsulto permite ao pretor expulsar de Roma filósofos e rétores gregos. Posteriormente, os censores Lúcio Licínio Crasso e Gneu Domício Enobarbo expressam sua reprovação quanto às escolas dos latini rhetores, por meio de um edito emanado em 92 a.C., que constitui o objeto de estudo do presente trabalho.

Em uma primeira parte (item 2), trata-se das motivações do edito, alvo de grande discussão na literatura especializada, que oscila entre a identificação de razões políticas para a reprovação censória e, mais recentemente, a afirmação de que o que os magistrados buscam proteger é um modelo tradicional de educação retórica.

Em seguida (item 3), é apresentada a questão central a ser respondida pelo artigo, qual seja, se o edito dos censores efetivamente causou o fechamento das escolas dos rétores latinos.

A resposta, diante do silêncio do texto do edito como referido nas fontes latinas, é apresentada com base na investigação dos poderes exercidos pelos censores em seu regimen morum, em seu controle dos costumes romanos, notadamente a imposição de uma nota censoria, a fim de verificar quais as possíveis consequências do edito de 92 a.C. e se elas poderiam incluir, ainda que de forma indireta, o fechamento das escolas (itens 4 e 5). 


\title{
1. O EDITO E SUAS MOTIVAÇÕES
}

As fontes latinas mencionam a promulgação de um edito dos censores Lúcio Licínio Crasso e Gneu Domício Enobarbo, no ano de 92 a.C., em que manifestavam sua desaprovação em relação às escolas dos rhetores Latini, surgidas algum tempo antes. Suetônio, em sua obra sobre os gramáticos e rétores, após destacar que a disciplina da retórica foi recebida com dificuldade em Roma, onde chegou a ser proibida, menciona duas medidas tomadas contra seus professores: a primeira é um senatusconsulto do ano de 161 a.C., em que se concederam ao pretor amplas faculdades para expulsar de Roma os filósofos e rétores gregos; a outra é um edito de 92 a.C., cujo texto é reportado pelo historiador romano:

\begin{abstract}
Renuntiatum est nobis, esse homines qui novum genus disciplinae instituerunt, ad quos inventus in ludum conveniat; eos sibi nomen imposuisse Latinos rhetoras; ibi homines adolescentulos dies totos desidere. Maiores nostri, quae liberos suos discere et quos in ludos itare vellent, instituerunt. Haec nova, quae praeter consuetudinem ac morem maiorum fiunt, neque placent neque recta videntur. Quapropter et iis qui eos ludos habent, et iis qui eo venire consuerunt, videtur faciundum ut ostenderemus nostram sententiam, nobis non placere.

Foi-nos relatada a existência de homens que estabeleceram um novo tipo de ensino, e que a juventude se reúne com eles em suas escolas; que eles se autodenominaram "rétores latinos"; que homens bastantes jovens passam dias inteiros nelas. Os nossos antepassados estabeleceram o que desejavam que seus filhos aprendessem e que escolas queriam que frequentassem. Essas práticas novas, que acontecem contrariamente à prática e à tradição ancestral, não nos aprazem nem parecem corretas. Em razão disso, parece que devemos cuidar para que apresentemos nosso parecer tanto aos que dirigem tais escolas como aos que têm o costume de frequentá-las: isso não nos apraz. ${ }^{1}$
\end{abstract}

O texto do edito, que é reproduzido também por Aulo Gélio, ${ }^{2}$ não contém senão uma motivação genérica baseada na contrariedade do novo tipo de ensino em relação às práticas e tradições dos antepassados. É Cícero, por sua vez, quem reconstrói as razões de Crasso para a emanação do edito, fazendo-o dizer, no De oratore, que agiu contra as escolas dos rétores latinos (definidas como ludi impudentiae) em razão de sua superficialidade, pois que voltadas apenas ao ensino da ousadia e da exercitatio linguae, sem um mínimo de doctrina e conhecimentos mais amplos (humanitate digna scientia), o que as tornava uma ameaça ao desenvolvimento intelectual dos jovens oradores:

Verborum eligendorum et conlocandorum et concludendorum facilis est vel ratio vel sine ratione ipsa exercitatio; rerum est silva magna, quam cum Graeci iam non tenerent ob eamque causam iuventus nostra dedisceret paene discendo, etiam Latini, si dis placet, hoc biennio magistri dicendi exstiterunt; quos ego censor edicto meo sustuleram, non quo, ut nescio quos dicere aiebant, acui ingenia adulescentium nollem, sed contra ingenia obtundi nolui, conroborari impudentiam. [94] Nam apud Graecos, cuicuimodi essent, videbam tamen esse praeter hanc exercitationem linguae doctrinam aliquam et humanitate dignam scientiam, hos vero novos magistros nihil intellegebam posse docere, nisi ut auderent; quod etiam cum bonis rebus coniunctum per se ipsum est magno opere fugiendum: hoc cum unum traderetur et cum impudentiae ludus esset, putavi esse censoris, ne longius id serperet, providere.

É fácil o método, ou mesmo a prática sem método, de escolher as palavras, dispô-las, encerrá-las em cláusulas. Vasta é a matéria dos tópicos de estudo e, como os gregos já não a dominavam e nossa juventude praticamente a desaprendia ao aprender, surgiram também professores latinos—-pelos deuses! — nos últimos dois anos. Quando

1 Suet. gramm. 25. Tradução de Adriano Scatolin, inédita, utilizada com autorização do autor.

2 Gell. 15,11,2, no item relativo ao senatusconsulto de 161 a.C. e que contém, segundo o autor, "as palavras do edito dos censores, pelo qual foram desaprovados e reprimidos aqueles que começaram a estabelecer e exercer a disciplina da retórica em Roma." (verba edicti censorum, quo inprobati et coerciti sunt, qui disciplinam rhetoricam instituere et exercere Romae coeperant). 
censor, eu os suprimira com meu edito, não por não querer, como diziam que não sei quem alegava, que se aguçassem os talentos dos jovens, mas, pelo contrário, por não desejar que os talentos embotassem, que a impudência se fortificasse. [94]. De fato, percebia que entre os gregos, fossem eles o que fossem, havia, além desse exercício da língua, um mínimo de doutrina e de cultura digno de conhecimento. Já no caso desses novos professores, entendia que não eram capazes de ensinar senão a ousadia, algo que, mesmo quando ligado a coisas boas, deve ser fortemente evitado por si mesmo. Como se ensinava apenas isso e como aquela era uma escola de impudência, considerei que era dever de um censor cuidar para que aquilo não se espalhasse. ${ }^{3}$

Uma referência a tais escolas parece ser encontrada numa carta que Cícero envia a Ticínio e que é conservada por Suetônio. Ali Cícero, nascido em 106 a.C., descreve como, em sua juventude, um certo Plócio começou a ensinar retórica em latim e como muitas pessoas acorriam a sua escola, o que Cícero também desejava mas acabou não fazendo em razão do conselho que lhe foi dado por doctissimi homines, os quais lhe afirmaram ser mais proveitosa a realização de exercícios em grego. ${ }^{4}$

Se considerarmos que, dentre os homens experientes que contiveram Cícero em seu ímpeto juvenil, estivesse Crasso (e talvez os Cévolas, de quem Cícero também foi discípulo), podese ver aí já uma oposição extraoficial às escolas dos rétores latinos, que depois se manifesta no edito de 92 a.C.

A partir do final do século XIX, contudo, e com base na teoria de F. MARX, editor da Rhetorica ad Herennium, muitos têm desconfiado das motivações invocadas por Crasso (seja no edito ou em sua reconstrução por Cícero) e afirmado que a medida tomada pelos censores foi orientada, na verdade, por razões políticas, pois as escolas dos rétores latinos seriam uma ameaça ao poder da aristocracia, já que o ensino da retórica em latim a tornaria acessível a outras ordens sociais que não dominavam o idioma grego. Além disso, haveria uma ligação entre Plócio e Mário (inimigo da nobilitas), ${ }^{5}$ o que levaria a pensar nessas escolas como um viveiro de ideias democráticas, reprimidas pelos censores sob o pretexto de que seu modelo de ensino era incompatível com a tradição. ${ }^{6}$

3 Cic. de orat. 3,93-94. As traduções do De oratore utilizadas e mencionadas no presente artigo são da lavra de A. SCATOlin, A invenção no Do orador de Cícero: Um estudo à luz de Ad familiares I,9,23, Tese de Doutorado, Faculdade de Filosofia, Letras e Ciências Humanas da Universidade de São Paulo, São Paulo, 2009, tese em cujo apêndice se encontra uma tradução completa desse diálogo ciceroniano. Em 3,95, Crasso deixa claro não se opor ao ensino em latim: Quamquam non haec ita statuo atque decerno, ut desperem Latine ea, de quibus disputavimus, tradi ac perpoliri posse, patitur enim et lingua nostra et natura rerum veterem illam excellentemque prudentiam Graecorum ad nostrum usum moremque transferri, sed hominibus opus est eruditis, qui adhuc in hoc quidem genere nostri nulli fuerunt; sin quando exstiterint, etiam Graecis erunt anteponendi. "Porém, ao tomar tais medidas e decisões, não perco as esperanças de que essas questões que discutimos sejam ensinadas e aperfeiçoadas em latim, pois tanto a nossa língua como a natureza permitem que aquela antiga e excelente prudência dos gregos seja aplicada a nossa prática e tradição. Mas há necessidade de pessoas instruídas, algo que, pelo menos neste domínio, ainda não aconteceu. Porém, se um dia surgirem, deverão ser colocados acima até dos gregos."

4 Suet. gramm. 26: L. Plotius Gallus. De hoc Cicero in epistola ad M. Titinnium sic refert: Equidem memoria teneo, pueris nobis primum Latine docere coepisse Plotium quendam. Ad quem cum fieret concursus, quod studiosissimus quisque apud eum exerceretur, dolebam mihi idem non licere. Continebar autem doctissimorum hominum auctoritate, qui existimabant Graecis exercitationibus ali melius ingenia posse. "Lúcio Plócio Galo. Sobre ele Cícero relata o seguinte, numa carta a Marco Ticínio: 'Na verdade, recordo-me que, quando menino, um certo Plócio foi o primeiro a ensinar [sc. retórica] em latim. Como um grande número de pessoas acorria a sua escola e os mais estudiosos praticavam com ele, eu sofria por não poder fazer o mesmo. Era refreado, porém, pela autoridade de pessoas extremamente doutas, que consideravam que se podia estimular melhor os talentos com exercícios gregos." Tradução de Adriano Scatolin, inédita, utilizada com autorização do autor.

5 Ligação inferida do texto de Cic. Arch. 9,20, em que se relata que Mário admirava Plócio e desejava que ele louvasse em verso seus feitos: Itaque ille Marius item eximie L. Plotium dilexit, cuius ingenio putabat ea quae gesserat posse celebrari.

6 Cf. a descrição da tese política por A. MANFREDINI, L'Editto 'de coercendis rhetoribus latinis' del 92 a.C., in SDHI XLII (1976), pp. 99 e 114, em que menciona uma série de autores que aderiram a essa interpretação do edito. O mesmo 
É esta a tese adotada, por exemplo, por R. PICHON, para quem o ensino dos rétores latinos buscava tornar acessível a retórica não somente por meio do emprego do latim, mas também em razão da falta de uma formação mais ampla, que simplificava a matéria. Essa vulgarização, segundo ele, além de criar, aos olhos dos optimates, apenas agitadores e ambiciosos, o que era preciso evitar, ameaçava o domínio da aristocracia nessa área, ao que ela responde com o edito dos censores, que certamente não estava defendendo os professores gregos contra a concorrência dos professores latinos. ${ }^{7}$

G. ACHARD, embora não trate especificamente do edito de 92 a.C., que considera como uma evidência da desconfiança que os romanos nutriam em face dos rhetores, pode ser inserido na corrente que entrevê motivações mais ou menos políticas na resistência a esses profissionais. $\mathrm{O}$ autor nota que, ao mesmo tempo em que a arte da palavra se tornou algo muito estimado em Roma e que os rhetores podiam desempenhar um importante papel junto aos magistrados, aconselhando na confecção de um discurso, na escolha de argumentos e na propaganda eleitoral, eles permaneciam na sombra, sendo difícil identificar o responsável por uma ou outra invenção ou preceito, ou mesmo quem foi o professor de algum dos oradores ilustres mencionados, por exemplo, no Brutus. ${ }^{8}$

E a principal razão para tanto, segundo ele, não reside simplesmente no fato de serem frequentemente gregos ou na baixa posição social por eles ocupada (não raro eram ex-escravos), já que muitos rétores gregos são elogiados na literatura romana, alguns libertos como Gneu Flávio conseguiram ascender na escala social e vários gramáticos, mesmo sendo libertos, carregavam consigo o nomen de seu patrono, o que jamais ocorre com os rhetores. A verdadeira razão para mantê-los na sombra residiria, isto sim, no próprio poder da arte que ensinavam: a gramática era um saber inofensivo, mas a retórica podia ter uma eficácia temível. Desse modo, era preciso fazer uma separação nítida entre quem, como os rétores, podia ensinar os primeiros preceitos aos cidadãos e aqueles que podiam colocar a palavra a serviço da república como advogados ou magistrados, os oratores, o que tinha implicações também na transmissão do saber retórico, sempre controlada pelos principes, tanto nos moldes tradicionais do aprendizado prático (tirocinium fori) quanto na escrita dos manuais em latim. ${ }^{9}$

pode ser encontrado em M. T. LuZZATO, Lo scandalo dei "Retori latini". Contributo alla storia dei rapporti culturali fra Grecia e Roma, in Studi Storici 43, n. 2 (2002), p. 303. Um bom resumo da tese se encontra também em S. F. Bonner, Education in Ancient Rome: From the Elder Cato to the Younger Pliny, London-New York, Routledge, 1977, pp. 71-72: "In the first place, it is pointed out that Plotius was, according to Cicero, a close friend of Marius, who admired his talents. It is then deduced that Plotius, who bore a plebeian name (he was pretty certainly a freedman) belonged to the democratic party, and would be likely to be a supporter of Marius, who was a self-made man. Crassus, on the other hand, moved among the aristocracy, and, being at enmity (so it is said) with Marius, could have determined to use his power to silence Marius' adherent."

7 L'affaire des rhetores latini, in REA 6 (1904), pp. 37-39 e 40: "Une des armes les plus fortes de l'aristocratie lui échapperait. On comprend qu'elle ait dî s'en inquiéter et qu'un de ses défenseurs ait dî essayer de s'y opposer." L. PERNOT, La rhétorique dans l'Antiquité, Paris, Librairie Générale Française, 2000, pp. 137-138, também faz referência à motivação política (reação aristocrática contra um instrumento de promoção dos populares), embora não deixe de lado a motivação de cunho intelectual, voltada contra o ensino superficial e utilitário. A. GWYNN, Roman Education from Cicero to Quintilian, Oxford, Clarendon, 1926, pp. 65-66, embora ressalte que o ensino em latim não era nenhuma novidade, defende a motivação política do edito pelas seguintes razões: é improvável que a mera incompetência dos professores motivasse uma medida tão drástica; além disso, considera Plócio Galo um integrante da facção democrática, devido a sua ligação com Mário e ao fato de, no ano de 56 a.C., ter ajudado na composição do discurso de acusação de Atratino, que seria plebeu (contra essa afirmação, veja-se A. MANFREDINI, L'editto cit., p. 124), contra M. Célio, um jovem aristocrata.

8 Les rhéteurs sous la République: des hommes sous surveillance?, in Ktèma 14(1989), p. 181.

9 Les rheteurs cit., pp. 184-186. Para o autor (p. 187), esse desejo de manter os rhetores à margem também faz com que, nos primeiros tempos, os exercícios se limitem à língua grega e a temas abstratos, sem relação estreita com a realidade. Segundo ele, "la difference de langue aboutit à ce que le monde de l'éducation et celui de la pratique ne se confondent pas. L'abstraction évite de mêler éducation et politique." 
A desconstrução, de forma mais detida, da tese segundo a qual a motivação do edito seria principalmente política pode ser encontrada em dois autores italianos que se debruçaram sobre o tema dos rétores latinos e do edito de 92 a.C. contra eles direcionado.

Num longo arrazoado, que aqui se apresenta de forma resumida, A. MANFREDINI busca refutar a ligação entre as escolas de retórica latinas e o movimento popular de inspiração mariana, afirmando, em primeiro lugar, ser discutível a identificação entre o Plotius quidam mencionado por Cícero na carta a Ticínio e L. Plócio Galo, cuja ligação com Mário é sugerida na passagem já mencionada do Pro Archias. Mas ainda que se admita a identificação, o liame entre Plócio e Mário é muito tênue e, do mesmo trecho de Cícero, também se pode depreender uma ligação do rhetor com o círculo de Lutácio Cátulo, cuja orientação política era nitidamente conservadora.

Além disso, segundo o autor, na década de 90 a.C., quando surgem as escolas de retórica mencionadas, Mário é um personagem praticamente inexistente na política romana e ainda apresenta vínculos com a nobilitas, não se podendo perceber nele uma inclinação para o partido democrático como a que demonstrará depois, durante a guerra social. Por fim, a própria nobilitas não é um corpo assim tão homogêneo e conservador, uma vez que é de algumas de suas alas mais progressistas, e não do partido popular, que surgem fermentos de reforma de caráter democrático. Lúcio Licínio Crasso e Gneu Domício Enobarbo fariam parte desse setor mais moderado, o que torna difícil afirmar que emanaram seu edito contra os rétores porque o ensino deles era democrático. ${ }^{10}$

M. T. LuZZATO, por sua vez, sem negar a identificação entre o Plotius quidam e L. Plócio Galo, afirma que sua ligação com Mário era quase banal, limitando-se à aproximação para que o rétor e poeta celebrasse em verso os feitos de Mário, sem que se possa presumir qualquer comunhão de interesses políticos. A conhecida aversão de Mário ao grego não significa, por outro lado, uma preferência pelos estudos em latim, como eram exercidos na escola de Plócio, mas representa apenas a posição anti-intelectualista do homem de ação que se formou sem estudos e que se ri dos nobres que colocam toda sua confiança neles. ${ }^{11}$

A mesma autora destaca, ainda, que o uso do latim (que não era novidade no estudo da retórica em geral, tendo em vista os manuais já circulantes quando do surgimento da escola de Plócio) não representava nenhuma tentativa democrática de vulgarizar ou tornar mais acessível o ensino, já que os jovens que acorriam à escola não eram ignorantes, mas sim dotados de uma formação oratória (na Carta a Ticínio, Cícero fala em studiosissimi, o que se aplica a ele mesmo), o que somente era possível a quem já dominasse o idioma grego. Além disso, não seriam os jovens de condição inferior, mas sim os filhos da nobreza, os estudantes que se voltavam para o novo ludus, como ocorria com todas as novidades à moda grega que surgiam em Roma. ${ }^{12}$

E se o problema com as escolas dos Latini rhetores não era político, o que teria motivado os censores a promulgar um edito contra elas? M. T. LUZZATO destaca inicialmente que a utilização do termo rhetoras (palavra grega e declinada como no grego) pelos novos professores para definir a si mesmos, indicando o exercício de uma típica profissão grega (e que era alvo de desconfiança desde a Atenas clássica), já seria causa de escândalo para os romanos. ${ }^{13} \mathrm{~A}$ isso se somaria um preconceito generalizado contra a importação dos modos de vida gregos (o que não

${ }^{10}$ L'editto cit., p. 135, onde o autor apresenta o próprio resumo de seu argumento. A relação entre Mário e Plócio e discutida nas pp. 118-124; o papel de Mário durante a década de 90 nas pp. 124-127; as propostas de reforma vindas da própria nobilitas nas pp. 130-131 e a posição política dos dois censores nas pp. 132-134.

${ }^{11}$ Lo scandalo cit., p. 317. No mesmo sentido, M. C. AlEXANDER, Oratory, Rhetoric, and politics in the Republic, in W. DominiK e J. HALL, A companion to Roman Rhetoric, Oxford, Blackwell, 2007, p. 107.

${ }^{12}$ Lo scandalo cit., pp. 307; 316-317 (com relação à tipologia dos alunos), 321-326 (sobre o domínio prévio da retórica e do idioma grego). Igual é a posição de A. MANFREDINI, L'editto cit., p. 138 e 141.

${ }^{13}$ Lo scandalo cit., p. 308-309. 
impedia a admiração pelos frutos de sua cultura), ${ }^{14}$ dentre os quais se inclui a profissão de rhetor, e a utilização de impudentia para adjetivar as novas escolas seria um típico slogan anti-grego, presente em muitas passagens de Cícero. ${ }^{15}$

Mas o aspecto fundamental da oposição dos censores residiria na contrariedade do novo tipo de escola em relação ao tipo de ensino retórico tradicionalmente ministrado pelos romanos e que se dava por meio do tirocinium fori. ${ }^{16}$

Após aprender os primeiros rudimentos de retórica na escola de um gramático, um jovem romano passaria a acompanhar as atividades de um orador experimentado, aprendendo a arte oratória por meio da observação de seus discursos e do convívio com a atividade forense, ao que se somariam, em caráter secundário, ${ }^{17}$ seus estudos e exercícios de declamação domésticos, bem como a assistência às aulas de algum rhetor grego em passagem por Roma ou mesmo eventuais viagens para fazê-lo na própria Grécia. ${ }^{18}$

Já o ludus inaugurado por Plócio, que não tem como foco o mesmo conteúdo ensinado pelos gramáticos (à escola acorriam adulescentuli, jovens em idade viril e que já haviam recebido a formação inicial), busca prover uma formação mais avançada ${ }^{19}$ sem se pautar pelo modelo do tirocinium acima descrito, organizando-se como uma típica schola grega e valendo-se provavelmente do método das declamações. ${ }^{20}$ Com isso, retiravam os jovens da vida ativa a que deveriam se dedicar e faziam com que permanecessem dias inteiros ali, relegados ao mundo frívolo e fechado das escolas de declamação, que também serão alvo de crítica pelos autores do principado. ${ }^{21}$

${ }^{14}$ Em 129 a.C., por exemplo, Cipião Emiliano (admirador da cultura grega) se opôs á abertura de um ludus onde se ensinariam canto e dança à moda grega. Fragmentos de sua oração (cujas palavras combinam com as do edito de 92) revelam que o gosto pela cultura grega andava junto com o desprezo pela promiscuidade de seus costumes. Em 115114 a.C., os censores teriam expulsado artistas gregos de Roma (cf. Cassiod. Chron. a 639) e, no ano de 89 a.C., os censores teriam se voltado contra unguenta exotica e certos tipos de vinho grego e italiano (Plin. N. H. 13,5,24 e 14,6,95). Para M. T. LuZZATo (Lo scandalo cit., p. 307), o edito de 92 a.C. se volta contra uma prática grega, no mesmo espírito das providências mencionadas.

${ }^{15}$ Lo scandalo cit., pp. 312-314. Soma-se a isso um antitecnicismo de matriz isocrática e acadêmica (veja-se a crítica de Cícero a Hermágoras no de inventione) e uma desconfiança com relação aos rhetores, vistos como semeadores da desordem política, além de serem profissionais assalariados que talvez jamais tenham atuado nos tribunais, ao contrário dos oratores romanos. O rhetor é visto como um mestre sem talento pessoal e moralidade, mas ávido por ganhos, e talvez fosse essa a visão dos censores a respeito dos latini rhetores. (p. 313). A autora (p. 315) destaca que viver à moda grega é algo que os romanos reservam para seus espaços privados, mas que não querem permitir em público, mantendo ali o modo de vida pública dos maiores. Segundo ela, é um aspecto desse modo de vida grego que Plócio importa, a profissão de rhetor, e que os censores buscam coibir.

${ }^{16}$ M. T. LuZZATO, Lo scandalo cit., pp. 304-305; M. C. AleXANDER, Oratory cit., p. 107; C. MCNELIS, Grammarians and Rhetoricians, in W. DominiK e J. HALl (eds.), A companion to Roman Rhetoric, Oxford, Blackwell, 2007, p. 285.

${ }^{17}$ Como destaca A. MANFREDINI, L'editto cit., pp. 145.

${ }^{18}$ Sobre a diferença entre o modelo romano (exercitatio em solidão somada ao tirocinium fori) e o ensino grego (ginásio e escola), vejam-se, além da contraposição feita por Tácito, dial. 34,1 e 35,1, M. T. LuZZATO, Lo scandalo cit., p. 339 e ss, e A. MANFREDINI, L'editto cit, p. 144.

${ }^{19}$ Cf. M. T. LuZZATO, Lo scandalo cit., p. 337.

${ }^{20}$ Para A. MANFREDINI, L'Editto cit, p. 147, "la clamorosa novità introdotta dai rhetores Latini deve essere consistita nell'avere essi proposto l'insegnamento delle declamazioni come strumento di formazione superiore dell'oratore" $\mathrm{e}$ não simplesmente como exercícios que ele realizava em particular ou nas etapas inicias de sua formação com um gramático. Assim também S. F. BonNER, Roman Education cit., p. 72, e G. A. KENNEDY, The Art of Rhetoric in the Roman World. 300 B.C-A.D. 300, Princeton, Princeton University, 1972, p. 91-93, segundo o qual exercícios práticos de declamação já estavam presentes em Roma, como deixa claro o próprio Cícero ao falar de sua juventude (Brut. 309-310), mas eram feitos principalmente em grego, para permitir a correção por professores gregos, que, segundo ele, eram os melhores. O primeiro a ensinar exercícios declamatórios em latim teria sido L. Plócio Galo.

21 A. MANFredini, L'editto cit., p. 145-146. E. FAnTHAM, The Roman World of Cicero's De oratore, Oxford, Oxford University, 2004, p. 91; M. T. LuZZATO, Lo scandalo cit., pp. 318-320. Segundo a autora, em Roma apenas os pueri iam à escola e os jovens se dedicavam ao aprendizado na vida ativa. Os alunos de Plócio, no entanto, contrariando o costume, "siedono tutto il giorno in una scuola e non hanno piu tempo di frequentare il foro; da un punto di vista romano, si comportano come fossero ancora ragazzi, e soprattutto trascurano e rinviano i propri doveri istituzionali." 
Assim sendo, o que os censores defendem por meio da reprovação expressa no edito de 92 a.C. é um tipo de educação exercido desde havia muito e que o novo ludus punha em questão, ${ }^{22}$ sem que se possam excluir categoricamente outras motivações, como aquela de caráter cultural invocada por Crasso no De oratore (superficialidade do ensino e falta de formação mais ampla para os oradores), ou até mesmo um foco indevido de Plócio no falar em alta voz, que pode ter ofendido as concepções de oradores tradicionais como Crasso, ${ }^{23}$ além de uma preocupação de caráter político com o estímulo à demagogia por parte das novas escolas de retórica, como havia ocorrido com os Gracos, formados por um rhetor grego em sua casa. ${ }^{24}$

\section{A DISCUSSÃO ACERCA DO FECHAMENTO DAS ESCOLAS NAS FONTES ANTIGAS E AUTORES MODERNOS}

Esclarecidas as motivações do edito de 92 a.C., cabe questionar se ele teve como consequência o fechamento das escolas dos rétores latinos. Embora o próprio texto do edito não contenha nenhuma ordem nesse sentido e nem mesmo qualquer ordem, os autores latinos que o mencionam parecem dizer que o fechamento ocorreu.

Cícero, ao trazer a justificativa de Crasso, fá-lo empregar o verbo tollo (dentre cujos significados se pode mencionar "destruir, dar cabo de, pôr termo a, suprimir") para se referir às providências tomadas contra os novos professores surgidos (quos ego censor edicto meo sustuleram) $;{ }^{25}$ Tácito, cuja fonte parece ser o próprio Cícero, afirma que os censores mandaram fechar as escolas (cludere ludum impudentiae iussi sunt); ${ }^{26}$ Suetônio, antes de referir o texto do edito, fala que a retórica, em Roma, chegou a ser proibida de se exercer (prohibitam exerceri); Aulo Gélio, ${ }^{27}$ por seu turno, no título do capítulo relativo, diz tratar das palavras do edito pelo qual os professores foram inprobati et coerciti, e que os censores de coercendis rhetoribus Latinis ita edixerunt, sendo certo que o emprego do verbo coerceo, dentre cujas possíveis traduções temos "conter", "refrear", “deter", "suspender", “corrigir”, “punir”, "castigar”, pode induzir à impressão de que se trata do exercício da coercitio, um dos poderes dos magistrados romanos, empregado para se punir quem desobedecesse uma ordem por eles emitida.

(p. 319). Outro problema apontado pela autora (p. 320) é que, na escola, esses jovens não teriam como referência a auctoritas de um homem ilustre, mas apenas a habilidade técnica de um profissional de grau social inferior ao dos próprios alunos. O rhetor latino profissional, regendo-se por uma lógica quase de mercado, também se mostrava um personagem diverso daqueles gregos que ensinavam no âmbito doméstico das grandes famílias romanas e se punham numa relação de clientela com os patresfamilias, como destacam M. T. LUZZATO, Lo scandalo cit., pp. 315-316, R. PICHON, L'affaire cit., p. 39, e S. C. STROUP, Greek Rhetoric Meets Rome: Expansion, Resistance, and Acculturation, in W. DominiK e J. HALL (eds.), A companion to Roman Rhetoric, Oxford, Blackwell, 2007, p. 31, para quem as novas escolas trariam também uma textualização da retórica, retirando-lhe um pouco seu caráter prático e o aprendizado semi-amador de que se orgulhavam os romanos.

22 M. T. LuZZATO, Lo scandalo cit., p. 329.

${ }^{23}$ Cf. S. F. BonNER, Roman Education cit., pp. 72-73.

${ }^{24}$ M. T. LuZZATO, Lo scandalo cit., pp. 333-334. A autora, por outro lado, rejeita a ideia de que o medo dos censores era o surgimento de uma leva de jovens acusadores violentos, sugerida por J-M. DAVID, Promotion civique et droit à la parole: L. Licinius Crassus, les accusateurs et les rhéteurs latins, in MEFRA 91 (1979), pp. 135-181. Segundo ela (pp. 327-328), “naturalmente non nego affatto che vi potesse essere un'avversione politica per i singoli progetti portati avanti da una determinata factio accusatorum, ma il comportamento in se non era motivo di disturbo. Un romano fedele alla tradizione non era affatto scandalizzato dalla figura di un accusatore giovanissimo e spietato che dava inizio alla propria carriera politica procurando la rovina di um dirigente piu anziano e prestigioso: al contrario, la consuetudo citata nell'editto sicuramente includeva, come una parte caratteristica, proprio il rito dell'accusa precoce e feroce di un adulescentulus."

25 Cic. de orat. 3,93.

26 Tac. Dial. 35,1.

${ }^{27}$ Gell. 15,11,2. 
Boa parte dos autores modernos crê no fechamento das escolas por força do edito de 92 a.C. É o caso de M. T. LuZZATO, para quem embora elas tenham sido fechadas, não houve a expulsão dos rétores. ${ }^{28}$ A. GWYNN tem o fechamento como incontestável, ${ }^{29}$ R. PICHON ${ }^{30}$ fala em "décret de fermeture" e S. F. BONNER afirma que os censores "summarily ordered them to close the school". ${ }^{31}$

E. FANTHAM, por sua vez, embora saliente que a linguagem do edito não é coercitiva e não creia na expulsão dos professores, ao contrário do que ocorrera em 161 a.C., afirma que as escolas podem ter passado por um fechamento temporário por conta do edito, mas reganharam força já em 91 a.C., ${ }^{32}$ o que se depreende do fato de Crasso, no diálogo, empregar o verbo "suprimir" no pretérito mais que perfeito, evidência de que as escolas sobreviveram e persistiram ao edito. Uma confirmação disso, segundo a autora, se teria no fato de que Plócio continuou a exercer seu ofício de rhetor profissional até pelo menos 56 a.C.; outra confirmação estaria no texto da Retórica a Herênio, manual do século I a.C., que revela certo apreço de seu autor pelos rhetores latini, em razão de sua rejeição formal da prática de utilizar exemplos gregos e do tom político de seus exemplos mais extensos, que reflete simpatia pelos Gracos. ${ }^{33}$

C. MCNELIS, por seu turno, afirma que o edito não teve força jurídica, ao contrário do banimento dos rétores em 161 a.C., mas apenas indicava a insatisfação dos líderes romanos com a prática educacional do momento. ${ }^{34}$ É este também o pensamento de S. C. STROUP, que não nega sua estranheza diante de um edito que não visa expulsar, dispersar, punir os professores ou fazê-los parar suas atividades e que, diante disso e da popularidade dos rétores profissionais, não teve qualquer efeito duradouro. ${ }^{35}$ Conclusão semelhante se vê em A. MANFREDINI, que a partir da análise dos poderes dos censores no exercício da supervisão dos costumes (regimen morum), âmbito no qual se insere o edito de 92 a.C., entende que os censores buscaram apenas informar aos cidadãos, em tom paternalístico, a inadequação de certa conduta, e que a eficácia do edito dependeria sobretudo da auctoritas de quem o emanara, e não de qualquer força normativa inerente. $^{36}$

Embora, como se verá a seguir, não concordemos inteiramente com as conclusões de A. MANFREDINI, parece que o caminho por ele seguido para responder à questão relativa ao fechamento das escolas por força do edito é bastante frutífero. Diante disso, a sequencia da exposição passa a tratar da forma com que os censores exerceram seu controle dos costumes e que meios eles tinham a sua disposição para torná-lo eficaz, a fim de identificar quais seriam as consequências jurídicas do edito (cujo texto não contém nenhuma ordem de qualquer tipo) e se elas incluíam ou não o fechamento das escolas. ${ }^{37}$

${ }^{28}$ Lo scandalo cit., p. 302, nt. 5.

${ }^{29}$ Roman Education cit., pp. 61-62.

${ }^{30}$ L'affaire cit., p. 37.

${ }^{31}$ Roman Education cit., p. 72.

${ }^{32}$ The Roman World cit., p. 48.

33 The Roman World cit., pp. 91-92. A. MANFREDINI, L'editto cit., pp. 135-140, refuta a ideia de que a Retórica a Herênio seria um dos frutos da escola dos rétores latinos.

${ }^{34}$ Grammarians and Rhetoricians cit., p. 285.

${ }^{35}$ Greek Rhetoric cit., pp. 29-30.

${ }^{36}$ L'editto cit., p. 111.

${ }^{37}$ Sem adentrar na análise jurídica da questão, G. A. KENNEDY, The Art of Rhetoric cit., p. 91, sugere que a desaprovação manifestada pelos censores trazia consigo uma ameaça ao status de quem infringisse seus termos, circunstância que será seguida aqui como linha de raciocínio para explicar as consequências do edito. 


\section{O REGIMEN MORUM E OS PODERES DOS CENSORES}

Embora o recenseamento dos cidadãos romanos e suas propriedades tenha sido instituído durante o período monárquico e fosse realizado, durante o início da república, pelos próprio cônsules, cria-se, em 443 a.C., uma magistratura específica para desempenhar essa tarefa, uma vez que aqueles viviam ocupados nas guerras e o censo não se realizava havia tempo, não se podendo adiá-lo mais ainda. Trata-se da censura, magistratura ordinária (eleita em períodos regulares de tempo - a cada cinco anos) e maior (seus ocupantes detêm os auspicia e são eleitos nos comícios por centúrias, embora não possuam o imperium, ao contrário dos cônsules e pretores), aberta inicialmente apenas aos patrícios e, após 351 a.C., também aos plebeus. ${ }^{38}$

Inicialmente, suas funções se limitavam à realização do censo, mas com o tempo essa tarefa atraiu para os censores outros poderes e deveres, como a supervisão dos costumes do povo (regimen morum) e a administração e cuidado do patrimônio da república. ${ }^{39}$

$\mathrm{O}$ censo, a mais antiga delas, se realizava resumidamente da seguinte maneira: após a tomada de auspícios e o chamamento dos cidadãos, feito de forma separada para cada tribo, todo paterfamilias deveria comparecer perante os censores e declarar, mediante juramento, seu nome e as informações exigidas sobre seus bens, com base no arbítrio dos censores, mas também nas regras que os magistrados haviam promulgado antes do início do censo, por meio de um edito conhecido como lex censui censendo ou formula censoria. ${ }^{40} \mathrm{Na}$ avaliação dos bens, os censores gozavam de certa autonomia, podendo superestimar o valor a fim de impedir fraudes nas declarações ou impor uma taxação maior quando lhes parecesse adequado (o que ocorria, por exemplo, com os artigos de luxo).

\footnotetext{
${ }^{38}$ Sobre a origem da censura, veja-se E. M. A. MADEIRA, A censura na antiga Roma, in Revista da Faculdade de Direito de São Bernardo do Campo 14 (2008), pp. 153-155. Com ampla indicação de fontes romanas: G. LoNG, Censor, in W. SMITH, A Dictionary of Greek and Roman Antiquities, John Murray, London, 1875, pp. 260-261; TH. MOMMSEN, Droit Public Romain vol. IV, Paris, Thorin, 1894, pp. 1-3; F. DE MARTINO, Storia dela costituzione romana, Vol. I, Napoli, Jovene, 1951, pp. 271 e ss; GIZEWsKI, C., Censores, in Brill's New Pauly. Encyclopedia of the Ancient World. Antiquity. Volume 3, pp.103-104;

${ }^{39}$ G. LONG, Censor cit., p. 262; E. M. A. MADEIRA, A censura cit., pp. 154, 159, 161, onde a autora destaca que a administração do patrimônio implicava em "zelar pelos edifícios, estradas e obras públicas e decidir sobre o destino do ager publicus", como a locação e alienação. Um resumo das funções dos censores pode ser encontrado em Liv. 4,8,2: Idem hic annus censurae initium fuit, rei a parva origine ortae, quae deinde tanto incremento aucta est, ut morum disciplinaeque Romanae penes eam regimen, senatui equitumque centuriis decoris dedecorisque discrimen sub dicione eius magistratus, ius publicorum privatorumque locorum, vectigalia populi Romani sub nutu atque arbitrio eius essent. "Nesse ano foi criada a censura que, modesta em sua origem, viria a adquirir mais tarde tal importância que os costumes e normas de vida do povo romano seriam confiados a sua direção, que as questões de honra e desonra dos senadores e das centúrias de cavaleiros seriam submetidas à decisão dessa magistratura, e que a inspeção dos lugares públicos e particulares bem como as rendas do povo romano passariam a depender de sua aprovação e julgamento." Tradução de Matos Peixoto, História de Roma, Vol.I, 2a ed., São Paulo, Paumape, 1995. Também em Cic. leg. 3,3,7, vemos uma descrição das competências acumuladas pelos censores ao longo do tempo: Censoris populi aevitates suboles familias pecuniasque censento, urbis templa vias aquas aerarium vectigalia tuento, populique partis in tribus discribunto, exin pecunias aevitatis ordinis partiunto, equitum peditumque prolem discribunto, caelibes esse prohibento, mores populi regunto, probrum in senatu ne relinquonto. Bini sunto, magistratum quinquennium habento eaque potestas semper esto, reliqui magistratus annui sunto. "Compete aos censores o recenseamento do povo segundo as idades, a descendência, os escravos e o patrimônio; a inspeção dos templos, das ruas, das fontes, do tesouro e dos impostos; compete a eles dividir o povo em tribos, distinguindo os cidadãos por fortuna, por idades e de acordo com as ordens; manter o registro dos filhos dos cavaleiros e dos soldados da infantaria; coibir o celibato; velar sobre os costumes do povo; não deixar o indigno no Senado. Serão dois e a magistratura durará cinco anos, enquanto que os demais magistrados serão anuais. E seu poder será permanente.” Tradução de E. M. A. MADEIRA, A censura cit., p. 157 , ligeiramente modificada.

40 Liv. 4,8; 29,15; 43, 14 .
} 
Após coletar todas as informações necessárias, os censores redigiam as listas das tribos, centúrias e classes, uma vez que a posição de cada cidadão no exército e nas votações nos comícios era baseada em sua riqueza, daí a grande importância do censo. Os censores deveriam também confeccionar as listas dos senadores, retirando os nomes que julgassem indignos ou incluindo aqueles que passassem a merecer tal posição (é a chamada lectio senatus, que compete aos censores ao menos desde o Plebiscito Oviniano, datado entre 318 e 313 a.C). Da mesma forma, redigiam as listas dos equites, excluindo ou incluindo os cidadãos, conforme sua riqueza e moralidade. Depois disso, contavam-se os cidadãos e se anunciava o número deles, encerrando-se o censo por meio da cerimônia do lustrum, com o objetivo de purificar a cidade. ${ }^{41}$

Essa faculdade de, ao redigir as listas de cidadãos, excluir ou alterar a posição daqueles que fossem tidos como indignos de pertencer a uma determinada ordem (senatorial ou equestre), com o tempo conferiu aos censores o poder de avaliar a conduta moral dos cidadãos em público ou em particular e supervisionar sua conformidade com os costumes dos antepassados, de que os censores passaram a ser os principais guardiões. Essa faculdade, conhecida como regimen morum, ${ }^{42}$ passa a ser o aspecto mais destacado da censura e a razão para a grande reverência e temor com que tal magistratura era encarada pelos romanos. ${ }^{43}$

No exercício do regimen morum, se os censores não se limitassem, como era possível acontecer, a uma mera admoestação, expressavam sua desaprovação e puniam o cidadão por meio de uma nota, notatio ou animadversio censoria, aposta ao nome do indivíduo nas listas por eles confeccionadas. Tal punição era imposta apenas de acordo com sua consciência e senso de dever, uma vez que prestavam juramento de agir imparcialmente, mas, ao redigir as listas de cidadãos, eles deviam identificar o motivo da punição (subscriptio censoria), ${ }^{44}$ o que se mostra como uma limitação a seu arbítrio. Uma nota censoria gerava para o cidadão "apenas" a ignominia e não a infamia,${ }^{45}$ e essa decisão dos censores (válida apenas se ambos concordassem) não

${ }^{41}$ G. LONG, Censor cit., pp. 262-263; E. M. A. MADEIRA, A censura cit., pp. 157-158; GizewsKi, C., Census, in Brill's New Pauly. Encyclopedia of the Ancient World. Antiquity. Volume 3, pp.110-111.

42 As fontes romanas se referem a essa faculdade de maneiras diversas: Cic. leg. 3, 3,7 : Censores... mores populi regunto; Cic. Cluent. 42, 119 : Hunc... populi Romani... moribus praefuisse; 46, 129 : Praefectus moribus, magister veteris disciplinae ac severitatis; De prov. cons. 19,46 : Morum severissimum magisterium; Liv. 4,8,2 : tanto incremento aucta est, ut morum disciplinaeque Romanae penes eam regimen; Tito Lívio fala também no censor como moribus regendis creatus (Liv. 42, 3, 7) e moribus nostris praepositus (Liv. 40, 46, 1), além de empregar a expressão mores regere diversas vezes (Liv. 24, 18, 2; Liv. 41, 27, 13), ou simplesmente regere (Liv. 24, 18,7). Com relação à mesma função, veja-se ainda Dion. 18,19; Dion. 20,13,2-3; Plut. Cat. Ma. 16, e Lydus, De mag. 1,43.

43 Th. Mommsen, Droit Public Romain, vol. IV cit., pp. 53-54; G. Long, Censor cit., p. 263. Além disso, sobre o regimen morum, suas origens e exercício, veja-se A. E. Astin, Regimen Morum, in JRS 78 (1988), pp. 14-34; G. HUMBERT, Censores in Daremberg-Salio. Dictionnaire des Antiquités Grecques et Romaines, vol. 2, pp. 995-997; M. HuMM, Il regimen morum dei censori e le identità dei cittadini, in A. CORBINO, M. HUMBERT e G. NEGRI (orgs), Homo, caput, persona. La costruzione giuridica dell'identità nell'esperienza romana. Dall'epoca di Plauto a Ulpiano, Padova, Cedant, 2008, pp. 283-314; G. DE MARTINO, La censura in Livio, in Heliopolis. Culture e Civiltà XI-1 (2013), pp. 24-38; M. V. GIANGRIECO PESSI, Brevi riflessioni sul ruolo dela censura nella dialettica costituzionale della prima repubblica, in Societas - Ius. Munuscula di allievi a Feliciano Serrao, Napoli, Jovene, 1999, pp. 167 e ss.

44 Segundo Th. Mommsen, Droit Public Romain, Vol. IV cit, p. 63, nt. 2, os termos nota, notare e notatio são de uso mais geral (Cic. Cluent. 46,128; Cic. re pub. 4,10), sendo subscribere (Cic. cluent. 45,126 e 47,131; Gell. 4,20,6) e subscriptio (Cic. Cluent. 42,118 e 47, 132) expressões mais técnicas para indicar a anotação realizada pelos censores, assim como animadvertere e animadversio (Cic. cluent. 42,117 e 48,133; Cic. re pub. 4,6; Cic. off. 1,31,111). O termo notio, por sua vez, não designa a subscriptio, mas sim a tomada de conhecimento da infração que a precede, tanto que a palavra é frequentemente acompanhada de animadversio, iudicium ou outro termo correspondente.

45 É o que Cícero deixa claro em Cic. re pub. 4,7: "censoris iudicium nihil fere damnato nisi ruborem offert. Itaque, ut omnis ea iudicatio versatur tantum modo in nomine, animadversio illa ignominia dicta est.” A infâmia, segundo A. BERGER, Infamia, in Encyclopedical Dictionary of Roman Law, p. 500, era uma indignidade com consequências jurídicas mais nítidas, como a proibição de atuar nos tribunais ou funcionar como tutor, além de reflexos nos direitos sucessórios em alguns casos. Além disso, resultava não de uma atuação do censor, mas da condenação em certas ações (alguns delitos privados ou casos envolvendo contratos em que a boa-fé era fundamental). 
configurava um iudicium ou res iudicata, pois seus efeitos não eram duradouros e podiam ser removidos pelo próximo censor. ${ }^{46}$

Uma nota censoria podia ser imposta numa série de casos, que não estavam definidos de antemão e variavam conforme a consciência de cada censor, não havendo como expô-los em detalhes, diante da ampla casuística encontrada nas fontes romanas e a partir da qual se revelam apenas algumas das diretrizes que normalmente guiavam os censores. ${ }^{47}$

A imposição da nota, além da vergonha e provável perda de prestígio que gerava, podia redundar em outras consequências para o cidadão atingido, que variavam conforme seu status social. Eram elas a exclusão do Senado, a retirada do cavalo público de um cavaleiro, a mudança ou exclusão de uma tribo ou mesmo a degradação à condição de aerarius.

A motio ou eiectio senatu, que não impedia o retorno ao senado no próximo censo, podia se dar com a simples exclusão da lista, o que se percebia pela omissão dos nomes dos praeteriti senatores quando da leitura pública da lista ou, em alguns casos vir acompanhada de uma admoestação pública por parte do censor ao ler a lista de senadores. Nada impedia que um senador não fosse simplesmente excluído do senado, mas também de sua tribo e, assim, rebaixado ao grau mais inferior da escala social, o que, no entanto, era raro acontecer. Também a ademptio equi, ou seja, a perda do equus publicus por parte de um cavaleiro, podia ser combinada com o rebaixamento de grau.

A motio e tribu, ou seja, a exclusão do cidadão de sua tribo, originalmente equivalia à degradação à condição de aerarius, mas com o tempo, conforme se estabeleceu uma distinção entre as tribos rústicas e urbanas, a remoção da tribo significava a mudança de um cidadão para as tribos urbanas, menos respeitadas e cujo voto tinha menos valor.

A degradação à condição de aerarius (cidadão sem direito de voto nas assembleias e sujeito ao pagamento de uma taxa) podia ser imposta a qualquer pessoa, independentemente da ordem social a que pertencesse. Sendo a mais grave, por implicar uma diminuição considerável nos direitos políticos, ela incluía todas as outras, uma vez que um cavaleiro não podia se tornar aerarius antes de ser privado de seu cavalo público e o membro de uma tribo rústica deveria antes ser excluído dela. ${ }^{48}$

Para além do instrumento da nota censoria, voltado apenas contra indivíduos específicos, os censores podiam também se valer de seu poder de emanar editos (ius edicendi) para exercer o controle dos costumes por meio de publicações de caráter geral. ${ }^{49}$ É o que ocorreu, de forma

\footnotetext{
${ }^{46}$ A. Berger, Nota Censoria, in Encyclopedical Dictionary of Roman Law, p. 598; Th. Mommsen, Droit Public Romain, Vol. IV cit., pp. 62-63 e 66; GIZEWSKI, C., Nota censoria, in Brill's New Pauly. Encyclopedia of the Ancient World. Antiquity. Volume 9, pp. 826-827. G. LoNG, Censor cit., p. 263, segundo o qual a nota não parece que privasse um magistrado de seu cargo nem desqualificasse (juridicamente) alguém a concorrer às magistraturas, atuar como iudex ou servir ao exército, e cita o caso de M. Emílio, que foi feito ditador mesmo após uma animadversio censoria (Liv. 4,31).

${ }^{47}$ G. Long, Censor cit., p.264, em que o autor classifica em dois tipos as ofensas passíveis de punição pela nota: a) má conduta na vida privada, como o celibato em determinadas épocas (punido com a imposição de uma multa), a dissolução do matrimônio de forma inadequada, conduta imprópria com relação à mulher e filhos ou pais, luxo excessivo ou prodigalidade, desleixo no cultivo dos campos, crueldade contra escravos ou o desempenho de profissões desonrosas, dentre outras condutas; b) ações que ofendessem a moralidade pública, e que eram proibidas por meio de um edito, cuja desobediência, segundo o autor, sujeitava o indivíduo à imposição da nota. G. HuMBERT, Censores cit., p. 997, faz uma classificação diferente das ofensas passíveis de nota, distinguindo entre aquelas que ameaçam a prosperidade material da república e aquelas que ameaçam sua grandeza moral. Já TH. MoMMSEN, Droit Public Romain, Vol. IV cit., pp. 55-60, com farta indicação de fontes, elenca várias condutas que ensejaram a punição ao longo da história romana.

48 Descrição das consequências dada por G. LoNG, Censor cit., p. 264.

${ }^{49}$ G. HumBerT, Censores cit., p. 997.
} 
excepcional, com as punições financeiras impostas por Catão aos proprietários de objetos de luxo, bem como alguns editos sobre iguarias oferecidas nos banquetes, sobre a venda de perfumes exóticos, sobre o preço do vinho, ou no caso das escolas de retórica. Mas, segundo afirma E. Astin, tais medidas foram poucas, nada duradouras, e na maioria do tempo os censores atuavam por meio da nota censoria e apenas sobre alguns indivíduos, de cujos deslizes eles tomavam conhecimento imediatamente ou por meio de terceiros que funcionavam como acusadores, o que talvez tornasse a incidência de sua atuação menos ampla do que parece pela narrativa das fontes, interessadas nos casos curiosos e anedóticos. ${ }^{50}$

\section{A CONTRIBUIÇÃo dA ANÁLISE JURÍdiCA PARA A ELUCIDAÇÃo dA CONTROVÉRSIA RELATIVA AO FECHAMENTO DAS ESCOLAS DE RETÓRICA}

Segundo A. MANFREDINI, o fato do edito de 92 a.C. se inserir no contexto do regimen morum (o que fica claro pela referência a ludus impudentiae e pela competência dos censores para atuar também no âmbito da educação dos filhos) ${ }^{51}$ é fundamental para estabelecer quais fossem suas finalidades e para discutir a opinião segundo a qual os censores teriam coercitivamente banido os rhetores latini e decretado o fechamento das escolas. ${ }^{52}$

Em favor da tese do fechamento estaria o texto de Suetônio, onde a notícia de tal edito vem logo após a menção ao senatusconsulto de 161 a.C., que concedia ao pretor amplas faculdades de expulsar rétores e filósofos gregos de Roma, ou seja, que implicava no amplo exercício da função coercitiva. Além disso, Aulo Gélio, ao tratar das duas medidas (senatusconsultos e edito dos censores), fala do último como edito de coercendis rhetoribus Latinis e, de forma genérica, menciona a coercitio.

No entanto, a partir de um aspecto da análise sobre os poderes dos censores, notadamente o fato de não serem dotados de imperium, já se pode afirmar que, malgrado o termo empregado por Aulo Gélio, o caso dos rhetores em 92 a.C. não é um exemplo de emprego da coercitio, que A. BERGER define como o poder que tinham os magistrados romanos de garantir a obediência a suas ordens e punir ofensas menores por meio de atos de constrição ou repressão (prisões, multas, penhoras) contra os quais geralmente não havia recurso e que eram levados a cabo sem qualquer procedimento fixo, dependendo da discricionariedade do magistrado.$^{53}$ Esse poder, segundo TH. MOMMSEN, estava ligado ao imperium dos magistrados e não era exercido pelos censores senão de forma muito tênue, com a aplicação de multas, e jamais em relação a uma nota censoria. ${ }^{54}$

Segundo A. MANFREDINI, a explicação para o uso de coerceo em Aulo Gélio é que tanto ele quanto os autores modernos foram induzidos ao erro porque o edito de 92 a.C. encontra-se ligado a um episódio análogo e no qual realmente se fez uso do poder repressivo do pretor, mas a questão do fechamento das escolas se resolve pela análise do poder edital dos censores e da função normativa de cada categoria de edito.

\footnotetext{
${ }^{50}$ Regimen Morum cit, p. 26

${ }^{51}$ Cf. Dion. 20,13,2; Plut. Cat. Maior. 16 16. Th. Mommsen, Droit Public Romain, Vol. IV, p. 59, nt. 6, relaciona o edito expressamente com esse aspecto do regimen morum, levando em conta que ele contivesse mais do que uma simples advertência.

52 L'editto cit., p. 105.

${ }^{53}$ Coercitio, in Encyclopedical Dictionary of Roman Law, p. 393.

${ }^{54}$ Droit Public Romain, Vol. I, Paris, Thorin, 1893, p. 158, nt. 2, e p. 164.
} 
São indicados com a terminologia edictum os provimentos emanados pelos censores em relação: a) aos critérios para realização do censo (como em Liv. 43,14,5), ainda que o termo técnico mais preciso seja formula censendi, ${ }^{55}$ ou formula census $;{ }^{56}$ b) ao exercício de funções administrativas (as chamadas leges contractus, tratadas como editos em Liv. 39,44,8; 43,16,2) e c) também à supervisão dos costumes (como o edito de 92 a.C. e outros exemplos sobre os unguenta exotica, o vinho grego, e a repressão ao luxo). ${ }^{57}$

Mas a eficácia normativa de cada um desses "editos” é diversa. As leges censoriae (concessões para construção e manutenção de edifícios) têm uma eficácia normativa relevante e podem se fazer cumprir pelo censor por meios variados de constrição patrimonial. No que diz respeito à formula censendi, mesmo com relação às disposições ali contidas, as fontes não atestam nenhum poder coercitivo à disposição do censor para obter seu cumprimento ou punir os desobedientes. Pelo contrário, há testemunhos indicando que, quando isso se fazia necessário, o censor recorria à intervenção dos cônsules para levarem a cabo a repressão contra o incensus (que não comparece ao censo). ${ }^{58}$

Por fim, com relação aos editos em matéria de cura morum, as fontes são completamente omissas e o único exemplo certo de tal medida é o edito de 92 a.C., mas, com base nele, o que se pode afirmar, segundo A. MANFREDINI, é que tais editos se dirigiam a toda a coletividade, no intuito de informá-la, em tom paternalístico, acerca das condutas que os censores consideravam contrárias aos costumes tradicionais e que, em alguns casos, por serem praticadas no íntimo da vida doméstica, encontrariam sanção apenas na reprovação imposta pelos indivíduos a si mesmos em sua consciência. A eficácia dessas recomendações dependeria, portanto, apenas da auctoritas da própria magistratura ou daquela de cada censor em particular, afora o temor de ser atingido por uma nota. ${ }^{59}$

Para o autor, aliás, nem mesmo a nota pode ser considerada como sanção para o descumprimento de um edito relativo ao regimen morum, uma vez que as diversas fontes em que se relata a emanação de uma nota, com suas consequências (exclusão do senado, perda do equus publicus ${ }^{60}$ ou degradação à condição de aerarius) jamais vinculam a punição à violação de algum edito dos censores. E a própria nota não era uma punição assim tão eficaz, uma vez que poderia ser revogada no próximo censo e, para determinados estratos sociais (como os aerarii), não surtia efeito jurídico algum, mas apenas moral, gerando vergonha e ignomínia. ${ }^{61}$

Tais considerações, somadas ao fato de que o texto do edito de 92 a.C. não contém nenhuma ordem taxativa ou mesmo ameaças expressas, apresentando apenas uma advertência moral para toda a coletividade e não apenas para os promotores daquele ludus impudentiae, levam

55 Liv. 4,8,4 e 29,15,9.

56 Tab. Heracl. 1145 em FIRA 1,140.

57 A. MANFREDini, L'editto cit., p. 106. O autor nota também (p. 107-108) que o termo lex, por sua vez, também é utilizado para os atos administrativos dos censores, para a formula censendi e, em alguns casos, para se referir aos editos censórios relativos à cura morum, mas neste último caso a denominação é vista com suspeita (Mommsen, por exemplo, afirma que o termo é uma invenção de Plínio) e pode fazer pensar na verdade, em leis comiciais chamadas de censoriae apenas por terem caráter suntuário e por terem sido provavelmente estimuladas pelos censores, apesar de não serem eles os responsáveis pela proposição formal (rogatio).

58 A. MANFREDINI, L'editto cit., pp. 109-110.

${ }^{59}$ L'editto cit., p. 111, onde o autor ressalta que o caráter de recomendação está presente ainda no Império, quando era de se esperar que a censura assumisse um caráter mais cogente derivado da autoridade do príncipe. É o que se vê nos editos emanados por Cláudio na qualidade de censor (Suet. Claud. 16 utiliza o verbo admoneo para se referir a elas). Esse caráter normativo mais fraco dos editos dos censores é ressaltado também por TH. MoMmSEN, Droit Public Romain, Vol. IV cit., p. 50, nt. 3.

${ }^{60}$ Cavalo que os membros da ordem equestre recebiam da res publica ou que adquiriam com dinheiro fornecido por ela (aes equestre) e cuja manutenção era custeada pela república com o aes hordearium (Gai 4, 27).

${ }^{61}$ L'editto cit., p. 111-112. 
A. MANFREDINI a negar que o edito tenha determinado o fechamento das escolas ou a expulsão dos rhetores. ${ }^{62}$

No entanto, embora seja certo que o edito não determinou diretamente o fechamento das escolas e muito menos a expulsão dos rétores latinos, pode-se discordar do autor no que diz respeito à eficácia da nota censoria como meio de pressão tendente a garantir a eficácia do edito (considerando-se que sua intenção fosse realmente suprimir as escolas).

De fato, as fontes não vinculam a notação a editos específicos, o que dá a entender que os censores atuaram apenas com base em seu arbítrio e naquilo que identificavam como o mos maiorum ou a moral vigorante. Mas, se podia haver a punição mesmo sem uma previsão anterior, não seria de se esperar que ela ocorresse com muito mais razão quando existisse um edito declarando expressamente qual a conduta reprovável, como era o caso do edito de 92 a.C. relativo aos rhetores latini? Assim, não parece haver impossibilidade de que o edito em questão pudesse gerar a ignominia daqueles que agissem contra seu conselho.

E ainda que, como se viu acima, a eficácia de uma nota censoria não fosse perpétua e pudesse ser revogada no próximo censo, pode ser que mesmo assim ela funcionasse para desestimular a frequência às escolas dos rhetores latinos e, assim como ocorreu com Cícero, outros jovens tenham deixado de acorrer a elas, seja porque eles mesmos temessem a ignominia de uma possível notação, seja porque seus pais ou preceptores nutrissem tal preocupação.

Se, como afirma A. MANFREDINI, o edito não causou o fechamento das escolas, como se explicaria o emprego de sustuleram por Cícero $?^{63}$ Uma hipótese é que o verbo empregado, neste caso, não queira dizer realmente supressão ou fechamento, mas apenas certa repreensão dirigida aos rétores. Além disso, pode ser que Cícero tenha empregado o verbo de forma hiperbólica para indicar uma ação que realmente não tinha em mira consequências tão drásticas, mas apenas a admoestação dos jovens e a reprovação moral dos professores.

Mas se o verbo empregado realmente se referia ao fechamento, o que dizer? Que Cícero estaria inventando um fato? Não parece ser o caso, tendo em vista a preocupação com a correção histórica na construção do diálogo, como admite o próprio A. MANFREDINI ao defender a autenticidade do edito. ${ }^{64}$

O mais provável, nesse caso, é que o fechamento tenha ocorrido não como consequência direta do edito, o que parece impossível, já que ele não contém nenhuma ordem nesse sentido, mas em razão da falta de alunos, talvez barrados da mesma maneira que Cícero, por razões educacionais (era melhor aprender em grego) ou por medo de uma nota censoria, que parece uma

${ }^{62}$ L'editto cit., p. 112: "Alla luce di queste considerazioni-prime tra tutte, la mancanza di rilievo strettamente giuridico degli editti emanati a tutela dela moralità e l'assenza di um potere coercitivo in senso tecnico in capo ai censori - si può fondatamente respingere l'opinione secondo la quale $i$ censori del 92 hanno coercitivamente allontanato $i$ rhetores Latini e decretato lo scioglimento delle loro scuole." Segundo ele, quando os censores se viam diante de questões morais graves e que exigiam medidas mais drásticas, como intervenções coercitivas ou medidas normativas, só lhes restava inspirar leis suntuárias ou solicitar a intervenção do senado, como fizeram os censores de 97 a.C. para a abolição dos sacrifícios humanos. (Plin. N. H. 30,12)

${ }^{63} \mathrm{O}$ cludere... iussi sunt de Tácito é mais facilmente explicável se o fechamento não tiver ocorrido, uma vez que ele, além de não ter acesso ao texto do edito, se baseia em Cícero para construir seu relato e deve ter interpretado o sustuleram posto na boca de Crasso como indício do fechamento, ainda que Cícero não tenha dito expressamente isso.

${ }^{64}$ L'editto cit., p. 103: “Cicerone, sotto l'occhio atento dei contemporanei, molti dei quali dovevano ricordare l'evento accaduto pocchi decenni prima (nel 92), non può avere inventato l'emanazione dell'editto nè alterato profondamente i motivi che lo avevano ispirato." Acerca do tema, veja-se E. RAwson, Cicero the Historian and Cicero the Antiquarian, in JRS 62 (1972), pp. 33-45, R. E. JONES, Cicero's Accuracy of Characterization in His Dialogues, in American Journal of Philology 60.3 (1939), pp. 307-325, e A. LiNTOTT, Cicero as Evidence:A Historian's Companion, Oxford, Oxford University, 2008. 
sanção relativamente grave, a ser levada em consideração por um cidadão romano cioso de sua reputação.

De qualquer forma, pode ser que o edito não tenha tido eficácia duradoura e o fechamento tenha sido apenas provisório, tendo em vista o florescimento posterior das escolas de declamação e a presença de Plócio como rétor anos depois. ${ }^{65}$ Uma razão adicional para se duvidar da eficácia social do edito é o próprio fato de Cícero, ao fazer Crasso justificar sua ação, apontar para a existência de um questionamento e talvez oposição à medida por parte de um círculo da sociedade, demonstrando não haver consenso social com relação à medida tomada pelos censores.

O fato é que, mesmo com o edito de 92 a.C., o ensino da retórica continua a florescer em Roma. Gnifo ministra numa escola em 66 a.C.; ${ }^{66}$ Voltacílio Ploto, um liberto, abre uma escola na qual Pompeu vai estudar; a esses se somam outros e a retórica encontra seu espaço, talvez em grande parte devido à acomodação terminológica e ideológica feita por Cícero em seus trabalhos. ${ }^{67}$

\section{REFERENCIAS}

ACHARD, Guy, Les rhéteurs sous la République: des hommes sous surveillance?, in Ktèma 14 (1989), pp. 181-188.

ALEXANDER, Michael C., Oratory, Rhetoric, and politics in the Republic, in W. Dominik e J. Hall, A companion to Roman Rhetoric, Oxford, Blackwell, 2007.

ASTIN, Alan E., Regimen Morum, in JRS 78 (1988), pp. 14-34.

BERGER, Adolf, Encyclopedical Dictionary of Roman Law. Transactions of the American Philosophical Society, Volume 43, Part 2, Philadelphia, 1953.

BONNER, Stanley F., Education in Ancient Rome: From the Elder Cato to the Younger Pliny, London-New York, Routledge, 1977.

DAVID, Jean-Michel, Promotion civique et droit à la parole: L. Licinius Crassus, les accusateurs et les rhéteurs latins, in MEFRA 91 (1979), pp. 135-181.

DE MARTINO, Francesco, Storia della costituzione romana, Vol. I, Napoli, Jovene, 1951.

DE MARTINO, Gabriele, La censura in Livio, in Heliopolis. Culture e Civiltà XI-1 (2013), pp. 24-38.

FANTHAM, Elaine, The Roman World of Cicero's De oratore, Oxford, Oxford University, 2004.

GIANGRIECO PESSI, Maria Vittoria, Brevi riflessioni sul ruolo dela censura nella dialettica costituzionale della prima repubblica, in Societas - Ius. Munuscula di allievi a Feliciano Serrao, Napoli, Jovene, 1999, pp. 161-170.

GIZEWSKI, Carl, Censores, in Brill's New Pauly. Encyclopedia of the Ancient World. Antiquity. Volume 3, pp.103-104.

${ }^{65}$ Nesse sentido, P. L. SCHMIDT, P. Gallus, in Brill's New Pauly. Encyclopedia of the Ancient World. Antiquity. Volume 11, p. 403.

66 Suet. Gramm. 7,4.

${ }^{67}$ M. T. LuZZATO, Lo scandalo cit., p. 338; S. F. BonNER, Roman Education cit., p. 74; G. ACHARD, Les rheteurs cit., p. 188; G. A. KenNedy, The Art of Rhetoric cit., p. 96; L. PERnOT, La rhétorique cit., p. 138. 
GIZEWSKI, Carl, Census, in Brill's New Pauly. Encyclopedia of the Ancient World. Antiquity. Volume 3, pp.110-111.

GIZEWSKI, Carl, Nota censoria, in Brill's New Pauly. Encyclopedia of the Ancient World. Antiquity. Volume 9, pp. 826-827.

GWYNN, Aubrey, Roman Education from Cicero to Quintilian, Oxford, Clarendon, 1926.

HUMBERT, Gustave, Censores in Daremberg-Salio Dictionnaire des Antiquités Grecques et Romaines, vol. 2, pp. 995-997.

HUMM, Michael, Il regimen morum dei censori e le identità dei cittadini, in Corbino, Alessandro, Humbert, Michel, e Negri, Giovanni (orgs), Homo, caput, persona. La costruzione giuridica dell'identità nell'esperienza romana. Dall'epoca di Plauto a Ulpiano, Padova, Cedant, 2008, pp. 283-314.

JONES, Robert Epes, Cicero's Accuracy of Characterization in His Dialogues, in American Journal of Philology 60.3 (1939), pp. 307-325.

KENNEDY, George A., The Art of Rhetoric in the Roman World. 300 B.C-A.D. 300, Princeton, Princeton University, 1972.

LINTOTT, Andrew, Cicero as Evidence: A Historian's Companion, Oxford, Oxford University, 2008.

LONG, George, Censor, in W. Smith, A Dictionary of Greek and Roman Antiquities, John Murray, London, 1875, pp. 260-266.

LUZZATO, Maria Tanja, Lo scandalo dei "Retori latini". Contributo alla storia dei rapporti culturali fra Grecia e Roma, in Studi Storici 43, n. 2 (2002), pp. 301-346.

MADEIRA, Eliane Maria Agatti, A censura na antiga Roma, in Revista da Faculdade de Direito de São Bernardo do Campo 14 (2008), pp. 153ss.

MANFREDINI, Arrigo, L'Editto 'de coercendis rhetoribus latinis' del 92 a.C., in SDHI XLII (1976), pp. 99-ss.

MCNELIS, Charles, Grammarians and Rhetoricians, in W. Dominik e J. Hall (eds.), A companion to Roman Rhetoric, Oxford, Blackwell, 2007.

MOMMSEN, Theodore, Droit Public Romain, Vol. IV, Paris, Thorin, 1894.

PERNOT, Laurent, La rhétorique dans l'Antiquité, Paris, Librairie Générale Française, 2000.

PICHON, René, L’affaire des rhetores latini, in REA 6 (1904), pp. 37-41.

RAWSON, Elizabeth, Cicero the Historian and Cicero the Antiquarian, in JRS 62 (1972), pp. 33-45.

SCATOLIN, Adriano, A invenção no Do orador de Cícero: Um estudo à luz de Ad familiares I,9,23, Tese de Doutorado, Faculdade de Filosofia, Letras e Ciências Humanas da Universidade de São Paulo, São Paulo, 2009.

SCHMIDT, Peter L., P. Gallus, in Brill's New Pauly. Encyclopedia of the Ancient World. Antiquity. Volume 11, p. 403.

STROUP, Sarah Culpepper, Greek Rhetoric Meets Rome: Expansion, Resistance, and Acculturation, in W. Dominik e J. Hall (eds.), A companion to Roman Rhetoric, Oxford, Blackwell, 2007. 
DOUVERNY, Felipe Epprecht

Recebido em: 12 set. 2018.

Aceito em: 18 mar. 2019. 